\title{
Total Phenolic Contents and Free Radical Scavenging Activity of Guaiacum officinale L. Extracts
}

\author{
Suthira Maneechai ${ }^{1}$ and Vachiraporn Pikulthong ${ }^{2 *}$
}

Suthira Maneechai ${ }^{1}$ and Vachiraporn Pikulthong ${ }^{2 *}$ 'Department of Biology, Faculty of Science, Mahasarakham University, THAILAND

${ }^{2}$ Division of Biology, Department of Science, Faculty of Science and Technology, Suan Sunandha Rajabhat University, THAILAND

\section{Correspondence}

Dr. Vachiraporn Pikulthong

Division of Biology, Department of Science, Faculty of Science and Technology, Suan Sunandha Rajabhat University, Bangkok 10300, THAILAND

Phone numbers +6621601143

Facsimile numbers +6621601146

E-mail: vachiraporn.pi@ssru.ac.th

\section{History}

- Submission Date: 15-07-2017

- Review completed: 11-08-2017;

- Accepted Date: 31-08-2017

DOI : 10.5530/pj.2017.6.145

Article Available online http://www.phcogj.com/v9/i6

\section{Copyright}

(C) 2017 Phcog.Net. This is an openaccess article distributed under the terms of the Creative Commons Attribution 4.0 International license.

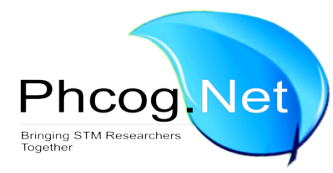

\begin{abstract}
Backgound: Guaiacum officinale L. is an alien species to Thailand. It is used as anti-arthritis and anti-rheumatoid agents in Indian folklore medicine. Objective: The present study was aimed to investigate total phenolic contents and free radical scavenging activity of the extracts from Guaiacum officinale L. (Zygophyllaceae). Methods: The plant parts including bark, twig and leaf were extracted using different solvents (ethyl acetate, water and ethanol). Total phenolic contents were determined by Folin-Ciocalteu Colorimetry method while free radical scavenging activity of the extracts was investigated by 2, 2-diphenyl-1-picrylhydrazyl (DPPH) radical scavenging activity assay. Results: The results show that the highest total phenolic content is found in the ethyl acetate twig extracts $(20.3 \pm 0.0031 \mu \mathrm{g}$ GAE/1 $\mu \mathrm{g}$ extracts). The ethanolic twig extracts had the highest free radical scavenging activity with $I C_{50}$ of $0.45 \pm 0.0188 \mathrm{mg} / \mathrm{ml}$. Conclusion: The extracts from Guaiacum officinale L. exhibit good anti-oxidant activity and may be suitable for development as drugs and supplementary food.
\end{abstract}

Key words: Total Phenolic Contents, Free Radical Scavenging Activity, Guaiacum officinale L, Ethanolic twig extracts, Ethyl acetate twig extracts.

\section{INTRODUCTION}

Guaiacum officinale L. (Thai name: Keaw Jao Jom) is a plant belonging to the family Zygophyllaceae. It is a tree with grayish bark. The leaves are opposite with round apex and terete petiole. The flowers are lightblue. For phytochemical constituents, it is reported that bark, ${ }^{1}$ flowers $^{2}$ and leaves ${ }^{3}$ of Guaiacum officinale L. mainly contain saponin such as guaianin and guaiacin. Saponin is found to have pharmacological activities including immunostimulant, anti-carcinogenic properties, anti-rheumatoid and hypocholesterolaemic effect. ${ }^{4,5}$

Recently, treatments of many diseases by alternative medicine or natural products are interesting. There are reports on biological activities of Guaiacum officinale L. such as anti-HIV activity of methanolic leaf, twig and seed extracts. ${ }^{5}$ The anti-oxidant activity of wood resin has been carried out. ${ }^{6}$ However, there is no report on the anti-oxidant activity of ethyl acetate, ethanol and water extracts of this plant. Therefore, the objectives of this study are to investigate total phenolic contents and free radical scavenging activity of the extracts from Guaiacum officinale L. The results from this study may be helpful for value addition and development of this plant as cosmetic, drugs and supplementary food.

\section{MATERIALS AND METHODS}

\section{Chemicals}

Gallic acid (Sigma-Aldrich), ascorbic acid (SigmaAldrich), sodium carbonate $\left(\mathrm{Na}_{2} \mathrm{CO}_{3}\right), 2,2$-diphenyl-1picrylhydrazyl (DPPH) (Sigma-Aldrich), Folin-Ciocalteu (Sigma-Aldrich), ethanol AR grade (Merck) and ethy acetate AR grade (Merck)

\section{Plant preparation and extraction}

Bark, twig and leaf of Guaiacum officinale L. were collected from campus of Suan Sunandha Rajabhat University, Bangkok, Thailand. Voucher specimens were deposited and identified at herbarium of National Park, Wildlife and Plant Conservation Department, Ministry of Natural Resources and Environment, Bangkok, Thailand. Plant parts were dried in hot air oven at $60^{\circ} \mathrm{C}$ until absolutely dry. They were then ground as fine powder. $600 \mathrm{ml}$ of different solvents (ethyl acetate, water and ethanol) were added to $30 \mathrm{~g}$ plant powder (bark, twig and leaf). The plant powders were then extracted by Soxhlet extraction apparatus at $60^{\circ} \mathrm{C}$ for 4 hours. The extracts were evaporated in water bath at $60^{\circ} \mathrm{C}$ and frozen dry in order to obtain crude extracts. The crude extracts were kept in dark container at room temperature until uses. 


\section{Determination of total phenolic contents}

Total phenolic contents were determined by Folin-Ciocalteu Colorimetry method (adapted from Amin et al., 2006). ${ }^{7}$ Gallic acid is used as standard (concentration of $12.5-100 \mathrm{mg} / \mathrm{ml}$ ). The crude extracts were dissolved in methanol. Folin-Ciocalteu reagent was added to $0.5 \mathrm{ml}$ of different extracts $(1 \mathrm{mg} / \mathrm{ml})$ and left for 5 minutes. $2 \mathrm{ml} \mathrm{Na}_{2} \mathrm{CO}_{3}$ was then added to the solution. The solutions were mixed and adjusted volume as $5 \mathrm{ml}$ by distilled water and left at room temperature for 2 hours. The solutions were then measured the absorbance at $760 \mathrm{~nm}$ wavelength. Total phenolic contents in the extracts were determined by comparison of standard curves between mg of Gallic acid equivalent/g extract.

\section{DPPH free radical scavenging activity study}

Free radical scavenging activity of the extracts was investigated by 2,2-diphenyl-1-picrylhydrazyl (DPPH) radical scavenging activity assay which is followed the study by Likhitwitayawuid et al. (2006). ${ }^{8} 100 \mu \mathrm{m}$ DPPH was prepared in methanol. The extracts were prepared in methanol at the concentration of $1 \mathrm{mg} / \mathrm{ml} .180 \mu \mathrm{LPPH}$ solution and $20 \mu \mathrm{l}$ extract solution were pipetted into microplate. The solutions were then incubated in dark room at room temperature for 20 minutes. These solutions were measured for absorbance by microplate reader (SPECTRO star Nano, BMG LabTech) at $517 \mathrm{~nm}$ wavelength. The absorbance of samples (As) was obtained. Methanol was used as blank and vitamin C was used as standard. Percentage inhibition of free radical was calculated by the following equation; \% radical scavenging $=[(\mathrm{Ac}-\mathrm{As}) / \mathrm{Ac}] \times 100$. The graph illustrating the relationship between concentrations of extracts and $\%$ radical scavenging is plotted and then $\mathrm{IC}_{50}$ was calculated.

\section{Statistical analysis}

Total phenolic contents and free radical scavenging activity were measured in 3 replicates $(n=3)$. All values were expressed as mean \pm S.D. The difference among means was analyzed by one-way ANOVA. The significant difference is at $\mathrm{p}<0.05$.

\section{RESULTS}

\section{The dry weight and percentage of yield}

The dry weight and percentage of yield of plant parts (bark, twig and leaf) extracted by different solvents (ethyl acetate, ethanol and water) is shown in Table 1 . The percentages of yield of ethyl acetate, ethanol and water bark extracts are $0.83,1.23$ and $4.67 \%$, respectively. The percentages of yield of ethyl acetate, ethanol and water twig extracts are 1.97, 15.03 and $8.99 \%$, respectively. The percentages of yield of ethyl acetate, ethanol and water leaf extracts are $1.44,14.50$ and $7.07 \%$, respectively.

\section{Total phenolic contents}

Total phenolic contents were calculated from standard curve of gallic acid $\left(y=4.1867 x+0.0215, R^{2}=0.996\right)$. It is found that ethyl acetate twig extracts have the highest total phenolic content $(20.3 \pm 0.0031 \mu \mathrm{g} \mathrm{GAE} / 1 \mu \mathrm{g}$ extracts), followed by ethanol and water twig extracts (12.9 \pm 0.0006 and $10.3 \pm 0.0010 \mu \mathrm{g} \mathrm{GAE} / 1 \mu \mathrm{g}$ extracts, respectively).

\section{DPPH free radical scavenging activity}

The results found that ethanolic twig extracts have the highest antioxidant activity with $\mathrm{IC}_{50}$ of $0.45 \pm 0.0188 \mathrm{mg} / \mathrm{ml}$, followed by ethyl acetate twig extracts and ethanolic bark extracts ( $\mathrm{IC}_{50}$ of $1.16 \pm 0.0054$ and $1.96 \pm 0.0243 \mathrm{mg} / \mathrm{ml}$, respectively). However, the standard vitamin $\mathrm{C}$ has anti-oxidant activity with $\mathrm{IC}_{50}$ of $0.0034 \pm 0.0002 \mathrm{mg} / \mathrm{ml}$ (Table 2.)

\section{DISCUSSION}

According to the results, it is found that twig extracts from Guaiacum officinale L. have the highest total phenolic content and anti-oxidant activity in comparison to those of bark and leaf extracts. Interestingly, ethyl acetate twig extracts have the highest total phenolic content followed by those of ethanol and water twig extracts. DPPH free radical scavenging activity study revealed that ethanolic twig extracts have the highest anti-oxidant activity with the lowest $\mathrm{IC}_{50}$ value in comparison to those of other extracts. When compared to those of vitamin $\mathrm{C}$, the plant

Table 1: The dry weight and percentage of yield of Guaiacum officinale L. extracts

\begin{tabular}{ccccccc}
\hline \multirow{2}{*}{$\begin{array}{c}\text { Solvent/ } \\
\text { Part of plants }\end{array}$} & \multicolumn{2}{c}{ Ethyl acetate } & \multicolumn{2}{c}{ Ethanol } & \multicolumn{2}{c}{ water } \\
\cline { 2 - 7 } & Dry weight $(\mathrm{g})$ & \% yield & Dry weight $(\mathrm{g})$ & \% yield & Dry weight $(\mathbf{g})$ & \% yield \\
\hline Bark & 0.25 & 0.83 & 0.37 & 1.23 & 1.40 & 4.67 \\
Twigs & 0.59 & 1.97 & 4.51 & 15.03 & 2.70 & 8.99 \\
Leave & 0.53 & 1.44 & 4.35 & 14.50 & 2.12 & 7.07 \\
\hline
\end{tabular}

Table 2: Total phenolic contents and DPPH free radical scavenging activity of Guaiacum officinale L. extracts

\begin{tabular}{cccc}
\hline Solvent & Plants part & DPPH $\left(\mathrm{IC}_{50} \mathrm{mg} / \mathrm{ml}\right) \pm \mathrm{SD}$ & Total phenolics $(\mu \mathrm{GAE} / 1 \mu \mathrm{g}$ extracts $)$ \\
\hline \multirow{2}{*}{ Ethyl acetate } & Bark & $2.11 \pm 0.0901^{\mathrm{c}}$ & $2.9 \pm 0.0032$ \\
& Twigs & $1.16 \pm 0.0054^{\mathrm{b}}$ & $20.3 \pm 0.0031$ \\
\multirow{3}{*}{ Ethanol } & Leave & $3.03 \pm 0.0698^{\mathrm{d}}$ & $6.4 \pm 0.0002$ \\
& Bark & $1.96 \pm 0.0243^{\mathrm{c}}$ & $7.6 \pm 0.0004$ \\
& Twigs & $0.45 \pm 0.0188^{\mathrm{a}}$ & $12.9 \pm 0.0006$ \\
\multirow{3}{*}{ water } & Leave & $5.71 \pm 0.1126^{\mathrm{e}}$ & $5.8 \pm 0.0009$ \\
& Bark & $>9.86$ & $0.1 \pm 0.0001$ \\
& Twigs & $2.65 \pm 0.2389^{\mathrm{d}}$ & $10.3 \pm 0.0011$ \\
& Leave & $3.32 \pm 0.0539^{\mathrm{d}}$ & $8.4 \pm 0.0004$ \\
\hline
\end{tabular}

Values are expressed as mean $\pm \mathrm{SD}(\mathrm{n}=3)$ of triplicate measurements. Different letters in the column indicate significant differences at $\mathrm{P}<0.05$ 

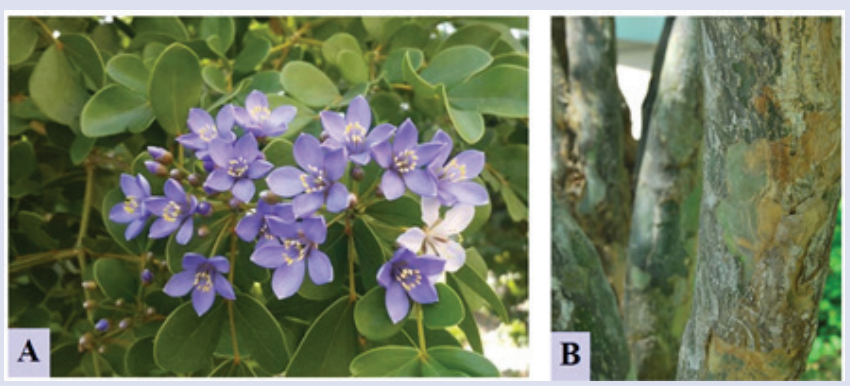

Guaiacum officinale L. A: flower, leave and twig; B: bark

extracts have higher $\mathrm{IC}_{50}$ value. This indicates that Guaiacum officinale $\mathrm{L}$. extracts have lower anti-oxidant capacity than those of vitamin C.

Lowe et al. (2014) reported anti-HIV activity of methanol and ethyl acetate extracts of leaf, twig and seed of Guaiacum officinale L. It was found that ethyl acetate extracts has higher HIV inhibitory activity than those of methanol extracts and leaf extracts have the highest anti-HIV activity. ${ }^{5}$ This report correspond with the present study in which ethyl acetate leaf extracts exhibit the higher anti-oxidant capacity than those of ethanol and water leaf extracts of this plant.

There is a study on anti-rheumatoid and anti-oxidant activity of resin from wood of Guaiacum officinale L. which was found that the extracts have high anti-rheumatoid and anti-oxidant activity in an animal model. ${ }^{6}$ This findings is similar results to the anti-oxidant activity of this plant in the in vitro study.

The results from this study revealed that twig extracts have higher total phenolic content and anti-oxidant activity in comparison to those of bark and leaf extracts. However, there is a few reports on twig extracts of this plant. The studies mainly focused on the biological activity and phytochemical constituents of bark, wood (resin) and flower extracts. Therefore, there should be further study on phytochemical constituents of twig extracts of Guaiacum officinale.

\section{CONCLUSION}

The results from this study revealed that Guaiacum officinale L.extracts exhibit anti-oxidant capacity. Therefore, there should be the investigations on other biological and pharmacological activities such as anti-microbial activity and anti-inflammatory activity. In additions, phenolic compound and flavonoids are beneficial to human health and disease prevention

\section{GRAPHICAL ABSTRACT}

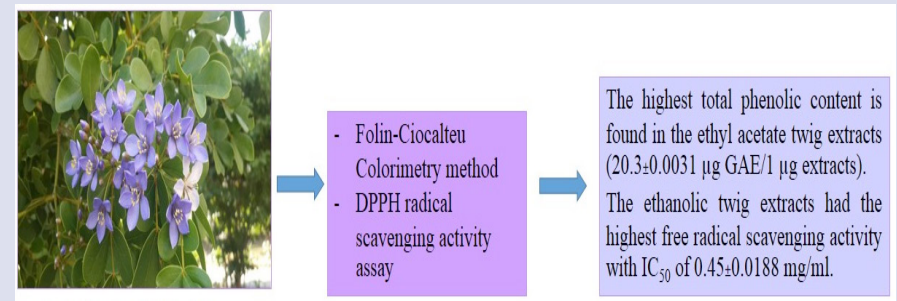

Guaiacum officinale L.

bark, twig and leaf (ethyl acetate, water, ethanol). including cardio-vascular disease and cancers ${ }^{9,10}$ The findings from this study provide information for selection of this plant for health promotion and further development as supplementary food.

\section{ACKNOWLEDGEMENT}

This research is financially supported by grants from Suan Sunandha Rajabhat University, Thailand. We are grateful to Faculty of Science, Mahasarakham University and Mahasarakham University for facility supports.

\section{CONFLICT OF INTEREST}

Authors declare no conflict of interest.

\section{ABBREVIATION USED}

DPPH: 2,2-diphenyl-1-picrylhydrazyl; GAE: Gallic acid equivalent; SD: Standard deviation; As: Absorbance of samples; Ac: Absorbance of controls.

\section{REFERENCES}

1. Saba N, Khatoon R, Ali Z, Ahmad VU. A new bidesmoside saponin from bark of Guaiacum officinale. Journal Chemistry Society of Pakistan. 2012;34(2):448-50.

2. Saba N. Guaianin N, a new saponin from flowers of Guaiacum officinale. Pakistan

3. Journal of Scientific and Industrial Research. 1993;36:54-6.

4. Ahmad VU, Perveen S, Bano S. Guaiacin A and B from the leaves of Guaiacum officinale. Planta medica. 1989;55(3):307-8. DOI: 10.1055/s-2006-962014.

5. Francis G, Kerem Z, Makkar HP, Becker K. The biological action of saponins in animal systems: a review. British Journal of Nutrition. 2002;88(6):587-605. https://doi.org/10.1079/BJN2002725.

6. Lower HIC, Toyang NJ, Heredia A, Watson CT, Bryant J. Anti-HIV-a activity of the crude extracts of Guaiacum officinale L. (Zygophyllaceae). European Journal of Mrdicinal Plants. 2014;4(4):483-9. http:// DOI: 10.9734/EJMP/2014/7343.

7. Sarkar A, Datta P, Das AK, Gomes A. Anti-rheumatoid and anti-oxidant activity of homeopathic Guaiacum officinale in an animal model. Homeopathy. 2014; 103(2):133-8. http://dx.doi.org/10.1016/ j. homp.2013.08.006.

8. Amin I, Norazaidah Y, Hainida, KIE. Antioxidant activity and phenolic content of raw and blanched Amaranthus species. Food Chemistry. 2006:94(1):47-52 http:// DOI: 10.1016/j.foodchem.2004.10.048

9. Likhitwitayawuid K, Sornsute A, Sritularak B, Ploypradith P. Chemical transformations of ox resveratrol (trans-2,4,3,5-tetrahydroxystilbene) into a potent tyrosinase inhibitor and a strong cytotoxic agent. Bioorganic and Medicinal Chemistry Letters. 2006;16(21):5650-3. http:// DOI: 10.1016/j.bmcl.2006.08.018

10. Newmark HL. Plant Phenolics as Potential Cancer Prevention Agents Dietary Phytochemicals in Cancer Prevention and Treatment. Advances in Experimenta Medicine and Biology. 1996;401:25-34

11. Sudjaroen Y. Plant-derived phenolic antioxidants and cancer prevention. Thai Cancer J. 2009;29:126-34

\section{SUMMARY}

- The twig extracts from Guaiacum officinale L. have the highest total phenolic content and anti-oxidant activity in comparison to those of bark and leaf extracts.

- The ethyl acetate twig extracts have the highest total phenolic content followed by those of ethanol and water twig extracts.

- DPPH free radical scavenging activity study revealed that ethanolic twig extracts have the highest anti-oxidant activity with the lowest $I C_{50}$ value in comparison to those of other extracts.

\section{ABOUT AUTHORS}

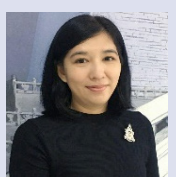

Dr.Vachiraporn Pikulthong: Obtained her Ph.D. in Bioscience, Faculty of Science, Kasetsart University, Thailand. Currently, she is the lecturer at Division of Biology, Department of Science, Faculty of Science and Technology, Suan Sunandha Rajabhat University, Thailand. She has experiences in the area of Biology working mainly in plant anti-oxidant, plant molecular biology and somatic embryogenesis.

Cite this article: Maneechai S and Pikulthong V. Total Phenolic Contents and Free Radical Scavenging Activity of Guaiacum officinale L. Extracts. Pharmacog J. 2017;9(6):929-31. 